\title{
Substance Distribution
}

National Cancer Institute

\section{Source}

National Cancer Institute. Substance Distribution. NCI Thesaurus. Code C71876.

The process of the transfer of a substance (particularly a drug) to and from the regions of the body, various tissues, organs, and body fluids, as well as dissemination of a substance in the tissues in the relative proportions. Distribution is determined by substance characteristics, tissue properties and blood flow. Rate of distribution depends on membrane permeability and blood perfusion, whereas its extend on plasma protein and intracellular binding, lipid solubility, and pH (pKa). 